
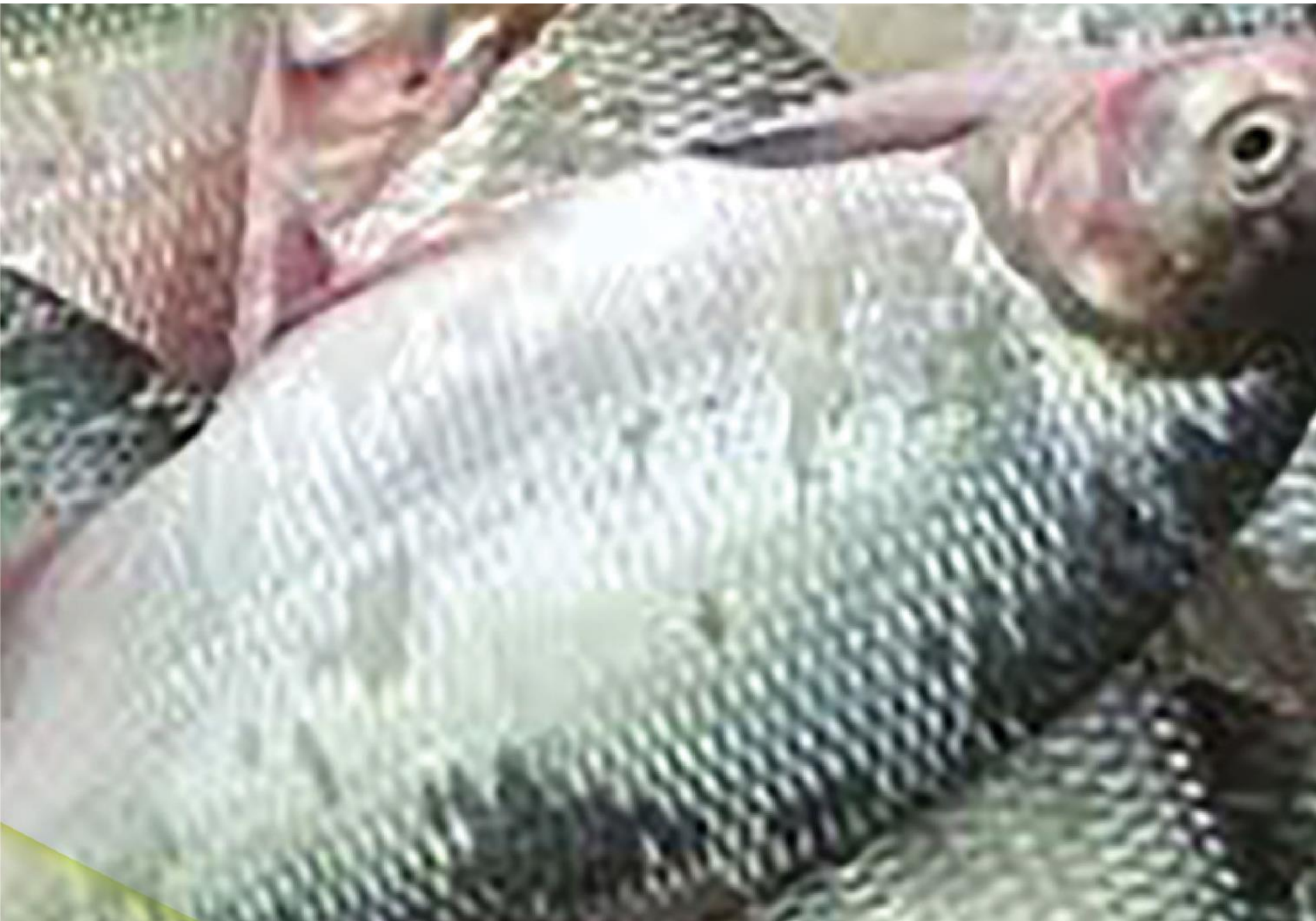

W.

Avaliação sensorial de matrinxã (Brycon amazonicus) enlatada com cobertura de óleo vegetal

Evaluation sensory of canned matrinxã (Brycon amazonicus) in vegetable oil

Caroline Dantas Mendes SILVA, Caroline Roberta Freitas PIRES, Diego Neves SOUSA

Patrícia Costa Mochiaro Soares CHICRALA e Viviane Rodrigues Verdolin SANTOS 


\title{
Avaliação sensorial de matrinxã (Brycon amazonicus) enlatada com cobertura de óleo vegetal
}

\author{
Evaluation sensory of canned matrinxã (Brycon amazonicus) in vegetable oil
}

OPPEN ACCESS
Caroline Dantas Mendes Silva ${ }^{1, \text { ID }}$
Caroline Roberta Freitas Pires ${ }^{1, *}$ (D)
Diego Neves Sousa ${ }^{2, \text { (DD }}$
Patrícia Costa Mochiaro Soares
Chicrala ${ }^{2, \text { ID }}$
Viviane Rodrigues Verdolin
Santos ${ }^{2, \text { iD }}$
1 Universidade Federal do Tocantins.
Palmas, TO, Brasil.
2 Empresa Brasileira de Pesquisa
Agropecuária-EMBRAPA. Palmas, TO,
Brasil.
*Autor para correspondência:
carolinerfpires@uft.edu.br

Informações adicionais

Recebido em: 28/03/2016

Aceito em: 20/08/2016

Publicado em: 30/09/2016

Editor:

Victor Hugo Gomes Sales

Instituto Federal do Amapá, Macapá, Amapá, Brasil. jbfs@ifap.edu.br

\section{Avaliação às cegas por pares}

Protocolos de revisão

Prot. $0982016 R 01$

Prot. $0982016 R 02$

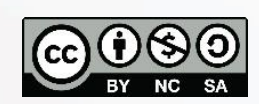

JBFS all rights

Copyright: @ 2016
ID JBFS0962016

DOI 10.18067/jbfs.v3i3.96

\section{RESUMO}

A indústria de conserva no Brasil apresenta problemas de abastecimento, visto que, a pesca extrativa da sardinha não atende à demanda do setor, provocando a necessidade de importar pescado de outros países. Neste contexto, surge a proposta de utilizar o matrinxã (Brycon amazonicus) como alternativa à sardinha (Sardinella brasiliensis) para enlatamento pela indústria de pescados. Neste trabalho objetivou-se avaliar a qualidade nutricional e sensorial de matrinxã enlatado em óleo vegetal. Para avaliar a aceitação foram utilizadas três amostras de pescado enlatado com cobertura de óleo vegetal, sendo: matrinxã, sardinha de água doce e sardinha de água salgada. Foi aplicado um teste de preferência e um teste de aceitação com escala hedônica de nove pontos. Não houve diferença significativa quanto à preferência entre o matrinxã e a sardinha de água doce, no entanto, o matrinxã e a sardinha de água salgada se diferenciaram significativamente, sendo que o matrinxã enlatado foi a mais preferida. Para o atributo cor, aroma e impressão global não houve diferença significativa entre os três pescados, já para o atributo sabor, o matrinxã apresentou maior média de aceitação se diferindo significativamente da sardinha de água salgada. Já na composição centesimal, o matrinxã apresentou um teor protéico de $28,67 \%$, umidade $51,67 \%$, lipídios $15,67 \%$ e minerais totais $2,67 \%$. Diante disso, conclui-se que o matrinxã consiste numa boa opção para indústria de pescados enlatados, visto que, apresentou boa qualidade nutricional e uma alta aceitação quando comparada com o pescado enlatado tradicional.

Palavras-chave: Pescado. Brycon amazonicus. Qualidade. Composição centesimal

\section{ABSTRACT}

The canning industry in Brazil has supply problems, since the extractive fishing sardine does not meet industry demand, causing the need to import fish from other countries. In this context, there is the proposal to use the matrinxã (Brycon amazonicus) as an alternative to sardines (Sardinella brasiliensis) for the canning of fish industry. This work aimed to evaluate the nutritional and sensory quality and matrinxã cans in vegetable oil. To evaluate the acceptance we used three canned fish samples with vegetable oil coverage, as follows: matrinxã, freshwater and saltwater sardine sardines. A preference test and an acceptance hedonic scale of nine points was applied. There was no significant difference in preference between the matrinxã and freshwater sardines, however, the matrinxã and saltwater sardines differ significantly, and canned matrinxã was the most preferred. For the color attribute, flavor and overall impression there was no significant difference between the three fish, as for the taste attribute, matrinxã presented higher acceptance significantly differing from saltwater sardines. In the chemical composition, the matrinxã showed a protein content of $28.67 \%$, moisture $51.67 \%$, $15.67 \%$ and total lipids $2.67 \%$ minerals. Therefore, it is concluded that the matrinxã is a good option for canned fish industry, as presented good nutritional quality and high acceptance compared to traditional canned fish.

Keywords: Fish. Brycon amazonicus. Quality. Chemical composition. 


\section{INTRODUÇÃO}

O Brasil é um país com grande potencial para a aquicultura, sendo o maior reservatório de água doce do planeta, com área litorânea estendendo-se por mais de oito mil quilômetros, diversidade de sistemas costeiros e com grande número de espécies nativas com potencial para cultivo, com cerca de 40 espécies de água doce entre outras marinhas. $^{1}$

Entre as espécies de água doce podemos citar o matrinxã, espécie de peixe brasileiro, encontrado nas bacias amazônicas, possui bom potencial de cultivo intensivo, crescimento rápido em cativeiro (700 a 1000g de peso no primeiro ano), carne nobre em condições de cultivo, facilidade em reprodução induzida e tem características apropriadas para pesca esportiva. Devido a isso desperta interesse para criação em cativeiro com fins comerciais (piscicultura). ${ }^{2,3}$

Segundo a FAO, no Ranking Mundial Aquícola de 2012, o Brasil ocupou a décima segunda posição, ficando abaixo apenas do Chile, entre os países da América. Entre 2005 e 2011, o consumo médio de pescado no Brasil subiu de 6,66 Kg per capita para $11,17 \mathrm{Kg}$, com um aumento em $67,7 \%,{ }^{4}$ seguindo essa perspectiva, as importações de pescado mais que dobraram, sendo em 2005, 145.932 Ton para 344.100 Ton em 2011. Em contrapartida, as exportações caíram em mais de $58,3 \%$ no mesmo período. $^{5}$

O aumento no consumo de pescado pelos brasileiros se deve ao crescimento na renda da população, redução da desigualdade social e a preocupação em adquirir uma alimentação mais saudável, além do aumento na produção e incentivo de Políticas Públicas, voltadas para o consumo e para a produção. ${ }^{4}$

Diante da necessidade de suprir o mercado interno, a pesca extrativa encontra dificuldades, como o período de defeso (paralisação temporária da pesca para preservação da espécie), relativo a cada espécie, além de problemas com a poluição que subtrai quantitativa e qualitativamente o pescado produzido. ${ }^{6}$

De acordo com Batista ${ }^{7}$ o Brasil apresenta um grave problema de abastecimento na indústria de conservas, visto que a pesca extrativa da sardinha, sua principal matéria-prima, não atende à demanda do setor, gerando um alto grau de ociosidade e/ou necessidade de importar pescado de outros países.

Portanto, o aumento do consumo de pescado pela população brasileira nos últimos anos, aliado a crescente importação de pescado de outros países como China, Chile e Vietnã, para o abastecimento interno e a diminuição nos níveis de exportação de pescado, ${ }^{5}$ deixam clara a necessidade de procurar novas alternativas, visando não apenas suprir o mercado interno, mas também aumentar o faturamento com exportações.

Surge então a proposta do enlatamento do matrinxã (Brycon amazonicus) com cobertura em óleo vegetal, como alternativa à sardinha (Sadinella brasiliensis) para enlatamento pela indústria de pescados.

Diante disso, o objetivo desse trabalho foi avaliar a qualidade nutricional e sensorial da matrinxã e a intenção de compra desse novo produto em comparação aos pescados enlatados já existentes e aceitos no mercado.

\section{MATERIAL E MÉTODOS}

\section{a) Matéria prima}

Os pescados matrinxã (Brycon amazonicus) foram obtidos de tanques de cultivo da cidade de Palmas, Tocantins, acondicionados em caixas isotérmicas em gelo e enviados para o processo de enlatamento, feito por uma indústria de conservas de pescado localizada no estado do Rio de Janeiro. No enlatamento utilizou-se cobertura de óleo vegetal (soja) para ambos os pescados e as latas apresentaram peso líquido de $125 \mathrm{~g}$ e peso drenado de $84 \mathrm{~g}$. As análises físico-químicas foram realizadas no pescado "in natura" e no pescado enlatado com cobertura de óleo vegetal.

\section{b) Análises físico químicas}

As análises de umidade foram determinadas pelo método gravimétrico com utilização de estufa até peso constante $\left(\mathrm{AOAC}^{8}\right.$; método 985.14), o aparelho de Soxhlet foi utilizado para a determinação do teor de extrato etéreo utilizando o hexano como solvente de extração $\left(A O A C^{8}\right.$; método 963.15). O teor de proteína foi determinado pela digestão da matéria orgânica e destilação no aparelho de Kjedahl, utilizando-se o fator 6,25 para o cálculo da proteína bruta $\left(\mathrm{AOAC}^{8}\right.$; método 991.20). A determinação da fração cinzas foi efetuada mediante incineração da matéria 
orgânica em forno mufla a $550-660^{\circ} \mathrm{C}$ (AOAC ; método 930.22). Todas as análises foram realizadas de acordo com os procedimentos estabelecidos pela Official Methods of the Association of the Agricultural Chemists. $^{8}$ O valor calórico das amostras foi calculado utilizando os fatores de conversão 4,0 para carboidrato e proteína e 9,0 para lipídios. ${ }^{9}$

\section{c) Análise Sensorial}

Para a avaliação da aceitação da matrinxã enlatada, utilizou-se como comparação amostras de sardinha de água doce (Triportheus sp.) obtidas da bacia amazônica e enlatadas com cobertura de óleo vegetal e amostras de sardinha de água salgada (Sardinella brasiliensis) enlatada com cobertura de óleo vegetal provenientes do mercado local.

Os testes de aceitação foram realizados na Universidade Federal do Tocantins, com 60 julgadores não treinados, homens e mulheres com idade entre 18 e 60 anos, consumidores de pescado enlatado. As amostras codificadas com algarismos de três dígitos contendo 15 gramas de pescado foram servidas para cada julgador, em cabines individuais iluminadas com luz fluorescente e acompanhadas de um copo de água mineral para a lavagem do palato e uma bolacha cream cracker. No teste de aceitabilidade foram avaliados os atributos de cor, aroma, sabor e impressão global, utilizando-se escala hedônica estruturada de nove pontos (1=desgostei muitíssimo; $5=$ nem gostei/nem desgostei; 9=gostei muitíssimo). ${ }^{10}$ Os provadores foram instruídos a julgar inicialmente a cor dos pescados pela observação visual e depois aroma e sabor.
A intenção de compra do produto foi avaliada através de uma escala de cinco pontos, onde 1=certamente não compraria e 5=certamente compraria. Para os testes sensoriais foi mantido o máximo de individualidade necessária para a avaliação das amostras pelos provadores. A equipe de aplicação foi responsável pelo controle, transmissão de instrução e orientação geral dos testes.

Para avaliar a preferência dos provadores utilizou-se um teste de ordenação, onde os provadores foram orientados a ordenar em ordem crescente as amostras de acordo com a sua preferência.

\section{Delineamento Experimental}

Adotou-se um delineamento inteiramente casualizado com sete repetições. Os valores da composição centesimal foram apresentados na forma de médias e desvio-padrão. Os resultados da análise sensorial foram submetidos à Análise de Variância (ANOVA) e ao teste de comparação de médias de Tukey, com a utilização do programa SISVAR. ${ }^{11}$ Os dados foram apresentados em tabelas e os atributos (cor, aroma, sabor, impressão global) na forma de histogramas relacionando o percentual de indivíduos e as notas atribuídas.

Os resultados obtidos pelo teste de ordenação foram tratados estatisticamente pelo método de Friedman.

\section{RESULTADOS E DISCUSSÃO}

$\mathrm{Na}$ Tabela 1 estão expressos os valores médios da composição centesimal de matrinxã "in natura".

Tabela 1. Composição centesimal $\left(\mathrm{g} \cdot 100 \mathrm{~g}^{-1}\right)$ das amostras de matrinxã "in natura"

Table 1. Centesimal composition $\left(g .100 \mathrm{~g}^{-1}\right)$ samples of matrinxã "in natura"

\begin{tabular}{ccccc}
\hline \multirow{2}{*}{ Pescado } & \multicolumn{4}{c}{ Composição Centesimal $\left(\mathrm{g} \cdot 100 \mathrm{~g}^{-1}\right)$} \\
\cline { 2 - 5 } & Umidade & Lipídios & Proteína & Mineral fixo \\
\hline Matrinxã & $78,2 \pm 0,63$ & $2,06 \pm 0,85$ & $16,98 \pm 0,36$ & $2,03 \pm 0,18$ \\
\hline
\end{tabular}

Média \pm desvio padrão.

Average \pm standard deviation. 
$\mathrm{Na}$ análise da composição centesimal de matrinxã "in natura" encontrou-se um valor de umidade de $78,2 \%$. Batista et al. ${ }^{12}$ ao avaliarem músculo de matrinxã Brycon cephalus post-mortem encontraram um valor de umidade de $72,3 \%$. Teores de umidade próximos ao presente estudo foram encontrados para a tilápia do Nilo (Oreochromis niloticus), na sardinha de água salgada (Opisthonema oglinum) e na sardinha papuda (Triportheus angulatus) ${ }^{13-15}$

Em relação ao teor de lipídios de matrinxã "in natura" foi encontrado um valor de $2,06 \%$. Na literatura observou-se que entre os pescados o teor lipídico variou de $2,03 \%$ a $7,5 \% \cdot \cdot^{12-14,16-18}$ Segundo
Ackman ${ }^{19}$ o matrinxã se enquadra na categoria dos peixes de baixo teor de gordura (entre 2 a 4\%).

O percentual de proteína encontrado no matrinxã de $16,98 \%$ está próximo de valores apresentados pela tilápia do Nilo, ${ }^{13}$ e no filé sem couro da palometa (Serrasalmus spilopleura). ${ }^{18}$

O teor médio de 2,03\% de cinzas no matrinxã, encontra-se dentro dos valores descritos na literatura, de 0,7 a 2,7\%. . $^{12,15,17,18}$

$\mathrm{Na}$ Tabela 2 estão expressos os valores médios da composição centesimal das conservas de matrinxã.

Tabela 2. Composição centesimal $\left(\mathrm{g} \cdot 100 \mathrm{~g}^{-1}\right)$ das amostras de matrinxã enlatado com cobertura de óleo vegetal.

Table 2. Centesimal composition $\left(\mathrm{g} .100 \mathrm{~g}^{-1}\right)$ of the samples of canned matrinxã with vegetable oil coverage.

\begin{tabular}{lccccc}
\hline \multirow{2}{*}{ Pescado Composição Centesimal $\left(\mathrm{g} .100 \mathrm{~g}^{-1}\right)$} \\
\cline { 2 - 6 } & Umidade & Lipídios & Proteína & $\begin{array}{c}\text { Mineral } \\
\text { fixo }\end{array}$ & E (kcal) \\
\hline Matrinxã & $51,67 \pm 0,75$ & $15,67 \pm 0,28$ & $28,67 \pm 0,48$ & $2,67 \pm 0,30$ & $255,71 \pm 2,30$ \\
\hline
\end{tabular}

Média \pm desvio padrão.

Average \pm standard deviation.

O matrinxã enlatado apresentou valores de umidade média de $51,67 \%$. No entanto, esse teor de umidade pode ser influenciado por diversos fatores tais como: espécie, época do ano, idade, sexo e estado nutricional do pescado, podendo variar entre 53 a $80 \%$ da composição centesimal do pescado. ${ }^{20}$

Quanto ao conteúdo lipídico o matrinxã apresentou um teor de $15,67 \%$. Teores de lipídios na mesma faixa observada no presente estudo foram encontrados em três marcas de sardinha enlatada com óleo vegetal de cobertura, ${ }^{21}$ e na sardinha com molho de tomate. ${ }^{22}$ No entanto, vale ressaltar que estes altos valores de lipídios podem estar associados à incorporação do óleo vegetal da conserva, uma vez que, o solvente utilizado na extração das gorduras leva a extração de outras substâncias como pigmentos tais como carotenóides e clorofilas, além de ésteres e ácidos graxos livres, vitaminas lipossolúveis e esteróis. ${ }^{22}$
O matrinxã apresentou um teor de $28,67 \%$ de proteína. Valores inferiores foram encontrados na sardinha em conserva ${ }^{22}$ e no pescado curimatã. ${ }^{15}$ Essas variações podem ser atribuídas a fatores tais como espécie, tamanho, sexo, época do ano, estágio reprodutivo, entre outros fatores endógenos e exógenos. ${ }^{24,25}$

Quanto ao teor de cinzas, o matrinxã apresentou $2,67 \%$. Os teores de cinzas encontrados em outros estudos com pescado enlatado oscilaram entre 2,53 e $2,95 \%,{ }^{21,22}$ no entanto, Batista ${ }^{7}$ encontrou uma média de $4,78 \%$ de cinzas na tilápia (Oreochromis niloticus) enlatada.

O valor calórico do matrinxã enlatado foi de $153,41 \mathrm{Kcal} / 60 \mathrm{~g}$, correspondente a uma densidade calórica de 2,56, valor este superior aos encontrados nos peixes in natura tainha $(1,17)$, guaiúba $(0,83),{ }^{14}$ curimatãs $(1,08)$, sardinha $(1,12)^{15}$ e na tilápia em conserva $(\approx 1,00),{ }^{7}$ podendo essa 
diferença estar associada às calorias adicionais fornecidas pelo óleo vegetal da cobertura.

Para verificar a aceitação das amostras de matrinxã em conserva pelos consumidores, realizou-se um teste sensorial de aceitação e intenção de compra, visto que, não há na literatura relatos de submissão deste pescado para o enlatamento. A análise sensorial foi realizada com três amostras (matrinxã enlatado com cobertura de óleo vegetal, sardinha de água doce enlatada com cobertura de óleo vegetal e a sardinha de água salgada com cobertura de óleo vegetal) e os dados estão apresentados na tabela 3.

De acordo com os resultados, observa-se que para o atributo cor, aroma e impressão global não houve diferença significativa entre os três pescados tendo seus valores situados na escala entre os termos "gostei ligeiramente" e "gostei moderadamente". Para o atributo sabor o matrinxã apresentou maior média de aceitação se diferindo significativamente da sardinha de água salgada enlatada, e não se diferindo da sardinha de água doce enlatada ao nível de $5 \%$ de significância pelo teste de tukey. Quanto à intenção de compra não foi observada diferença estatística significativa entre os três pescados situando na escala entre os termos "provavelmente compraria" e "certamente compraria".

Pizato et al. ${ }^{26}$ ao avaliarem sensorialmente a tilápia do nilo enlatada em óleo vegetal quando submetidas a tratamento térmico por 15 e 30 minutos, não encontraram diferença significativa entre os dois tratamentos quanto aos atributos sabor, odor, textura e avaliação global ( $p>0,05)$, obtendo todas as médias acima de sete pontos.

Para os atributos cor, aroma, sabor e impressão global (Figura 1 ) observa-se que mais de $70 \%$ dos provadores atribuíram notas entre 6 a 9, valores estes correspondendo entre os termos "gostei ligeiramente" e "gostei muitíssimo do pescado".

Dutra et al. ${ }^{27}$ avaliaram a aceitação do pacu, lambari e da tilápia processados em conserva (amostras cozidas sob pressão, com adição de temperos, em seguida resfriadas por 15 minutos e acondicionadas em bandejas separadas para cada espécie) por frequentadores de um mercado local, abordados individualmente. Foram avaliados os parâmetros de consistência, paladar, aroma, aparência e avaliação geral, considerando-os como ruim, aceitável, bom e muito bom. Quando observados os resultados percebeu-se que o pacu se sobressaiu das demais amostras nas avaliações da consistência, paladar, aroma e aparência, onde $45,2 \%$ dos provadores atribuíram valores de muito bom para as amostras.

Batista $^{7}$ avaliou sensorialmente tilápia em conserva submetida a três tempos de esterilização $(15,20$ e $30 \mathrm{~min})$, relatando que não houve diferença nos atributos sensoriais entre os tratamentos, no entanto afirmam que os tratamentos de 15 e 20 minutos apresentaram para o atributo sabor notas médias inferiores a 7,0.

Tabela 3. Valores médios das notas obtidas com análise sensorial das amostras de pescado.

Table 3. Average values of the notes obtained from sensory analysis of fish samples.

\begin{tabular}{cccccc}
\hline Pescado & Cor & Aroma & Sabor & $\begin{array}{c}\text { Impressão } \\
\text { Global }\end{array}$ & $\begin{array}{c}\text { Intenção } \\
\text { de Compra }\end{array}$ \\
\hline Matrinxã & $6,52 \mathrm{a}$ & $6,40 \mathrm{a}$ & $7,13 \mathrm{~b}$ & $6,73 \mathrm{a}$ & $4,08 \mathrm{a}$ \\
Sardinha de água doce & $6,17 \mathrm{a}$ & $6,50 \mathrm{a}$ & $6,67 \mathrm{ab}$ & $6,38 \mathrm{a}$ & $3,48 \mathrm{a}$ \\
Sardinha de água salgada & $6,53 \mathrm{a}$ & $6,83 \mathrm{a}$ & $6,37 \mathrm{a}$ & $6,43 \mathrm{a}$ & $3,30 \mathrm{a}$ \\
\hline
\end{tabular}

Letras iguais na mesma coluna não diferem significativamente $(p<0,05)$.

Letters equal in the same column do not differ significantly $(p<0.05)$. 

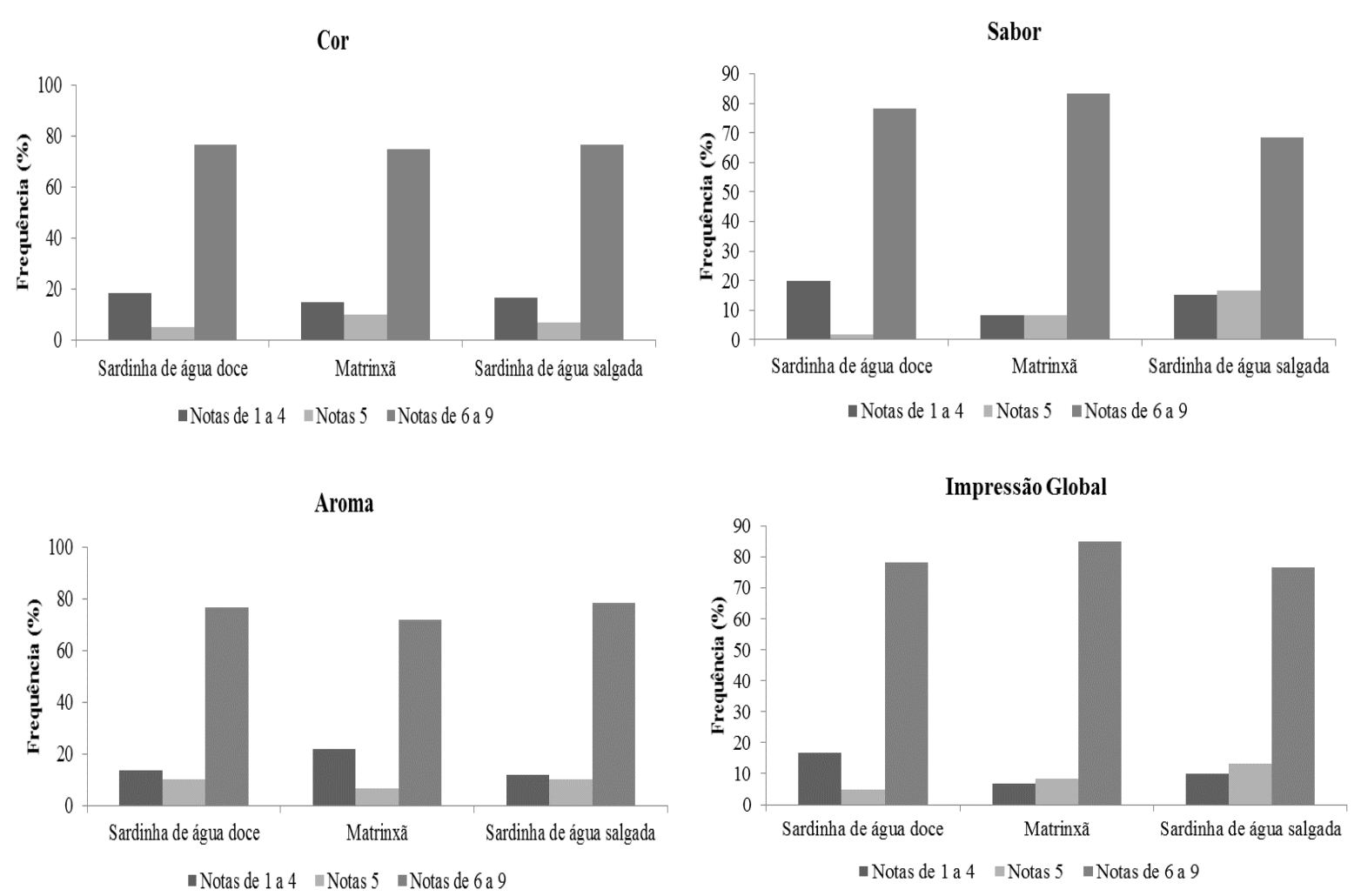

Figura 1. Histogramas de frequência quanto à avaliação sensorial de peixes enlatados

Figure 1. Frequency histograms as the sensory evaluation of canned fish

Com relação à intenção de compra (Figura 2) podemos observar que aproximadamente $87 \%$ dos provadores afirmaram que provavelmente e/ou certamente comprariam matrinxã enlatado, $64 \%$ afirmaram que provavelmente e/ou certamente comprariam a sardinha de água doce enlatada enquanto $53 \%$ afirmaram que provavelmente e/ou certamente comprariam a sardinha de água salgada enlatada. Apenas $7 \%$ dos provadores afirmaram que certamente ou provavelmente não comprariam matrinxã enlatado enquanto $26 \%$ afirmaram que certamente ou provavelmente não comprariam a sardinha de água salgada enlatada. Este resultado mostra a boa aceitação que o pescado matrinxã apresentou diante dos demais que são amplamente ofertados ao consumidor.

Colembergue et al..$^{22}$ fizeram a avaliação sensorial utilizando escala hedônica de nove pontos, onde "1-Desgostei muitíssimo" e "9-Gostei muitíssimo" para avaliar a aceitação da sardinha enlatada em molho com tomate, avaliando apenas o aspecto geral, sem diferenciação por atributos, obtendo um resultado de 7,56 na escala.

Torrano et al. ${ }^{23}$ avaliaram a aceitação de sardinha defumada considerando os atributos sabor, textura e preferência geral, obtendo notas que se situavam entre os termos "gostei" e "gostei muito" indicando que o produto teria boa aceitabilidade pelos consumidores.

Comparando-se os módulos da diferença com a diferença mínima significativa (DMS), conforme mostrado na Tabela 4 pode-se afirmar que não houve diferença estatística significativa quanto à preferência entre as amostras de matrinxã enlatado e sardinha de água doce enlatada e entre a sardinha de água doce e a sardinha de água salgada enlatada ao nível de $5 \%$ de significância. No entanto, a amostra de matrinxã enlatado e a sardinha de água salgada se diferenciaram significativamente ao nível de 5\% de significância, sendo que a amostra de matrinxã enlatado foi a mais preferida pelo teste de ordenação. 


\section{Intenção de Compra}

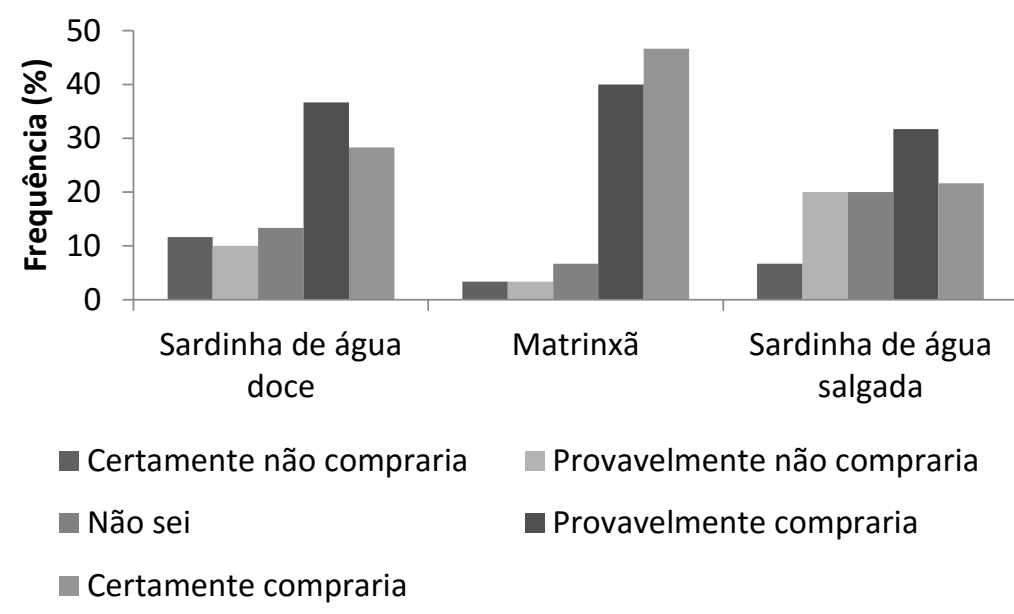

Figura 2. Histogramas de frequência quanto à intenção de compra de peixes enlatados

Figure 2. Frequency histograms as the sensory evaluation of canned fish

Tabela 4. Avaliação sensorial de preferência de peixes por ordenação para as amostras de matrinxã, sardinha de água doce e sardinha de água salgada

Table 4. Sensory evaluation preferably fish by ordering for samples matrinxã, freshwater sardines and saltwater sardines

\begin{tabular}{lc}
\multicolumn{1}{c}{ Diferença da soma de ordens } & Módulos da diferença \\
\hline Matrinxã e Sardinha de água doce & 22 (ns) \\
Matrinxã e Sardinha de água salgada & 35 \\
Sardinha de água doce e Sardinha de água salgada & 13 (ns) \\
\hline
\end{tabular}

(ns) = não significativo Diferença crítica de $\alpha=0,05=26$

(ns) $=$ not significant critical difference $\alpha=0.05=26$

Ao aplicar um teste de comparação pareada para avaliar a preferência do pescado tilápia em relação ao pescado enlatado tradicional, Batista $^{7}$ afirmou que não houve diferença significativa entre as duas amostras, sendo que ambas apresentaram características favoráveis ao consumo.

\section{CONTRIBUIÇÃO DOS AUTORES}

Os autores CDMS, CRFP, DNS, PCMSC e VRVS participaram do planejamento, condução do experimento, da elaboração e revisão final do artigo.

\section{CONFLITO DE INTERESSE}

Os autores declaram que não há conflito de interesse.

\section{FINANCIAMENTO}

Os autores reportaram que não houve suporte e auxílio financeiro durante o desenvolvimento da pesquisa.

\section{COMO CITAR ESSE DOCUMENTO}

ABNT

SILVA, Caroline Dantas Mendes et al. Avaliação sensorial de matrinxã (Brycon amazonicus) enlatada com cobertura de óleo. Journal of bioenergy and food science, v.3, n.3, p.161-169, 2016. DOI:10.18067/jbfs.v3i3.96

\section{APA}

Silva, C., Pires, C., Sousa, D., Chicrala, P., \& Santos, V. (2016). Avaliação sensorial de matrinxã (Brycon amazonicus) enlatada com cobertura de óleo Journal Of Bioenergy And Food Science, 3(3) 161169. DOI:10.18067/jbfs.v3i3.96 


\section{REFERÊNCIAS BIBLIOGRÁFICAS}

1. TESSLER, M. G.; GOYA, S. C. Processos Costeiros Condicionantes do Litoral Brasileiro. Revista do Departamento de Geografia, n.17, p.11-23, 2005. DOI 10.7154/RDG.2005.0017.0001

2. TAVARES-DIAS, M.; FRASCÁ-SCORVO, C.M.D.; CAMPOS-FILHO, E.; F. R. MORAES, F.R. Características Hematológicas de teleósteos Brasileiros. IV. Parâmetros Eritroleucométricos, Trombométricos e Glicemia do Matrinxã (Brycon cephalus Günther, 1869) (Osteichthyes: Characidae). Arquivo de Veterinária, v.15, n.3, p.149-153, 1999.

3. CRAEF, E.W.; RESENDE, E.K.; PETRY, P.; FILHO, A.S.Policultivo de matrinchã (Brycon sp) e jaraqui (Semaprochilodus sp.) em pequenas represas. Acta Amazonica, v. 16/17, p.33-42, 1986/1987. DOI: 10.1590/1809-43921987175042.

4. FEIRA NACIONAL DO CAMARÃO. Aquicultura na América Latina e Caribe - Situação Atual, Tendências e Perspectivas. 2014. Disponível em: <http://fenacam.com.br/pdf/fenacam2014/aquicultura/6 -aquicultura-na-america-latina-situacao-atual-eperspectivas__-felipe-matias.pdf >. Acesso em: 14 set. 2015.

\section{CONSELHO NACIONAL DE PESCA E AQUICULTURA}

(CONEPE). Balanço comercial 2015/julho. Acesso em: 16 set.2014.

6. CARVALHO, C.E.V.; FARIA, V.V.; CAVALCANTE, M.P.O.; GOMES, M.P. \& REZENDE, C.E. Distribuição de metais pesados em peixes costeiros bentônicos da região de Macaé, RJ., Brasil. Ecotoxicology and Environmental Restoration, v. 3, n. 2, p. 64-68, 2000.

7. BATISTA, L.X. Tecnologia de produção de conserva de tilápia (Oreochromis niloticus, Linnaeus, 1758 Linhagem chitralada). 2005. 38f. Dissertação (Mestrado em Recursos Pesqueiros e Aquicultura) - Programa de pós-graduação em recursos pesqueiros e aquicultura, Universidade Federal Rural de Pernambuco.

8. AOAC- Association of Official Analytical Chemists. Official methods of analysis of the Association Analytical Chemits. 16 ed., Gaithersburg: AOAC International, 1998.

9. MAHAN, L. K.; ESCOTT-STUMP, S. Krause: alimentos, nutrição e dietoterapia, 10 a edição, São Paulo: Roca, 2002.

10. CHAVES, J.B.P.; SPROESSER, R.L. Práticas de laboratório de análise sensorial de alimentos e bebidas. 1a ed. Viçosa: UFV; 2002. 81p.

11. FERREIRA, D.F. Sisvar: a computer statistical analysis system. Ciência e Agrotecnologia, v. 35, p. 1039-1042, 2011.

12. BATISTA, G.M.; LESSI, E.; KODAIRA, M.; FALCÃO, P.T. Alterações bioquímicas post-mortem de matrinxã Brycon cephalus (Günther, 1869) procedente da piscicultura, mantida em gelo. Ciência e Tecnologia de Alimentos, Campinas, v.24, n.4, p.573-581, 2004.

13. SUÑÉ PFEIFER SANT'ANNA, C.; MARCOS, L. Avaliação da Composição físico - química de amostras de tilápia (Oreochromis niloticus). In: XVIII Congresso de Iniciação Científica, XI Encontro de pós-graduação, I Mostra Cinetífica, 2009, Pelotas, Brasil, Universidade federal de Pelotas. - UFP, 2009.

14. ANDRADE, G.Q.; BISPO, E.S.; DRUZIAN, J.I. Avaliação da qualidade nutricional em espécies de pescado mais produzidas no Estado da Bahia. Ciência e Tecnologia de Alimentos, Campinas, v.29, n.4, p.721-726, 2009.

15. CAULA, F.C.B. et al. Teor de colesterol e composição centesimal de algumas espécies de peixes do Ceará. Ciência e Tecnologia de Alimentos, Campinas, v.28, n.4, p.959-963, 2008. v.28, n.4, p.959-963, 2008. DOI 10.1590/S010120612008000400031.

16. SANCHEZ, L.; GOMES, M.I.; SASE, L.E. Armazenamento da Pescada do Piauí, Plagioscions squamosissimus (Hechel, 1840), resfriadas. I. Evolução da composição química e alguns indicadores de frescor. Alimentos e Nutrição, São Paulo, v.2, p.73-82, 1990.

17. SALES, R.O.; MAIA, E.L. Composição química e classes de lipídios em peixes de água doce tambaqui, Colossoma macropom. Revista Brasileira de Higiene e Sanidade Animal, v.07, n.2, p.31-44, 2013. DOI 10.5935/1981 2965.20130009

18. SANTOS, A.B. Composição Bromatológica do Filé da Palometa (Serrasalmus sapilopleura Kner, 1860) na região de Uruguaiana-RS/Brasil. Revista da Faculdade de Zootecnia, Veterinária e Agronomia. Uruguaiana, v.13, n.2, p.166-170, 2006.

19. ACKMAN, R. G. Nutritional composition of fats in seafoods. Progress in Food and Nutrition Science, Oxford, v. 13, n. 1 p. 161-241, 1989.

20. ORDÓÑEZ, A. J. Tecnologia de Alimentos - Alimentos de origem animal. Artmed, 2005, vol.2. ed. 1, 280p, 2005.

21. LOIKO, M.R. Avaliação físico-química e perfil lipídico de Sardinha (Sardinella brasiliensis) e Atum (Thunnus tynnus) em óleo e molho. 2011. 38f. Monografia (Especialização). Curso de Especialização em Produção, Tecnologia e Higiene de Alimentos de Origem Animal, Universidade Federal do Rio Grande do Sul.

22. COlembergue, J.P.; GULARTE, M.A.; ESPÍRITO SANTO, M.L.P. Caracterização química e aceitabilidade da sardinha (Sardinella brasiliensis) em conserva adicionada de molho com tomate. Alimentos e Nutrição, v. 22, n. 2, p. 273-278, 2011.

23. TORRANO, A. D. M.; TOMASELLI, M.; GOMES, C. O. Estudo sobre um método de processamento para obtenção de sardinha defumada e sua aceitabilidade. 
Boletim CEPPA, v.8, n.1, p.28-34, 1990. DOI 10.5380/cep.v8i1.14496

24. LUZIA, L.A. et al. The influence of season on the lipid profiles of five commercially important species of Brazilian fish. Food Chemistry, Champaign, v.83, n.1, p.93-97, 2003. DOI 10.1016/S0308-8146(03)00054-2

25. MOREIRA, A.B. et al. Fatty acids profile and cholesterol contents of three Brazilian Brycon freshwater fishes. Journal of food Composition and Analysis, London, v.14, n.6, p.565-574, 2001. DOI 10.1006/jfca.2001.1025
26. PIZATO, S. et al. Avaliação da qualidade tecnológica apresentada pela tilápia do Nilo (Oreochromis niloticus) enlatada. Ciências Agrárias, Londrina, v.33, n.2, p.667674, 2012. DOI 10.5433/16790359.2012v33n2p667

27. DUTRA, F.M. Avaliação sensorial do processamento em conserva, utilizando-se as espécies: tilápia (Oreochromis niloticus), lambari (Astianax spp) e pacu (Piaractus mesopotamicus). Revista Brasileira de Produtos Agroindustriais, v14, n.3, p.239-244, 2012. 